Gold as an Inflation Hedge?

\author{
by \\ Dipak Ghosh, University of Stirling \\ Eric J. Levin, University of Stirling \\ Peter Macmillan, University of St. Andrews \\ Robert E. Wright, University of Stirling, CEPR and IZA
}

January 2002

\begin{abstract}
This paper attempts to reconcile an apparent contradiction between short-run and long-run movements in the price of gold. The theoretical model suggests a set of conditions under which the price of gold rises over time at the general rate of inflation and hence be an effective hedge against inflation. The model also demonstrates that short-run changes in the gold lease rate, the real interest rate, convenience yield, default risk, the covariance of gold returns with other assets and the dollar/world exchange rate can disturb this equilibrium relationship and generate short-run price volatility. Using monthly gold price data (19761999), and cointegration regression techniques, an empirical analysis confirms the central hypotheses of the theoretical model.
\end{abstract}

JEL Classification: D4

Key Words: $\quad$ gold prices, inflation, hedging, long-run, short-run 


\section{Gold as an Inflation Hedge? ${ }^{1}$}

\section{Introduction}

The demand for gold can be divided into two categories. The first is the "use demand", where it is used directly in the production of jewelry, medals, coins, electrical components, etc. The second is the "asset demand" for gold, where it is used by governments, fund managers and individuals as an investment. The asset demand for gold is traditionally associated with the view that gold provides an effective "hedge" against inflation and other forms of uncertainty. However, the reality is somewhat different. Gold may be an inflation hedge in the long-run but it is also characterised by significant short-run price volatility (Aggarwal, 1992).

Figure 1 plots the nominal price and "inflation hedge" price of gold in the period 1895 to 1999 (annual averages). The inflation hedge price is the dollar price that gold would have to be in order to maintain its 1895 purchasing power (as measured by the US consumer price index). In 1895 the price of gold was $\$ 20.70$ per ounce, or about $\$ 379$ in 1995 dollars, while in 1995 it was \$387--virtually no change in the real value of gold over a one-hundred year period. Fitting a trend line indicates that the real price of gold increased on average by only 0.3 per cent per year in this hundred-year period. For the period 1895 to 1999 , the price

Acknowledgement: The authors are grateful to Andrew Smith of Mitsui Global Precious Metals for much valuable advice and assistance. The comments of Sheila Dow, Brian Loasby, Gary Shea and Tom Torrence were most helpful. Of course, full responsibility for all remaining errors and shortcomings rests solely with the authors. 
Figure 1:

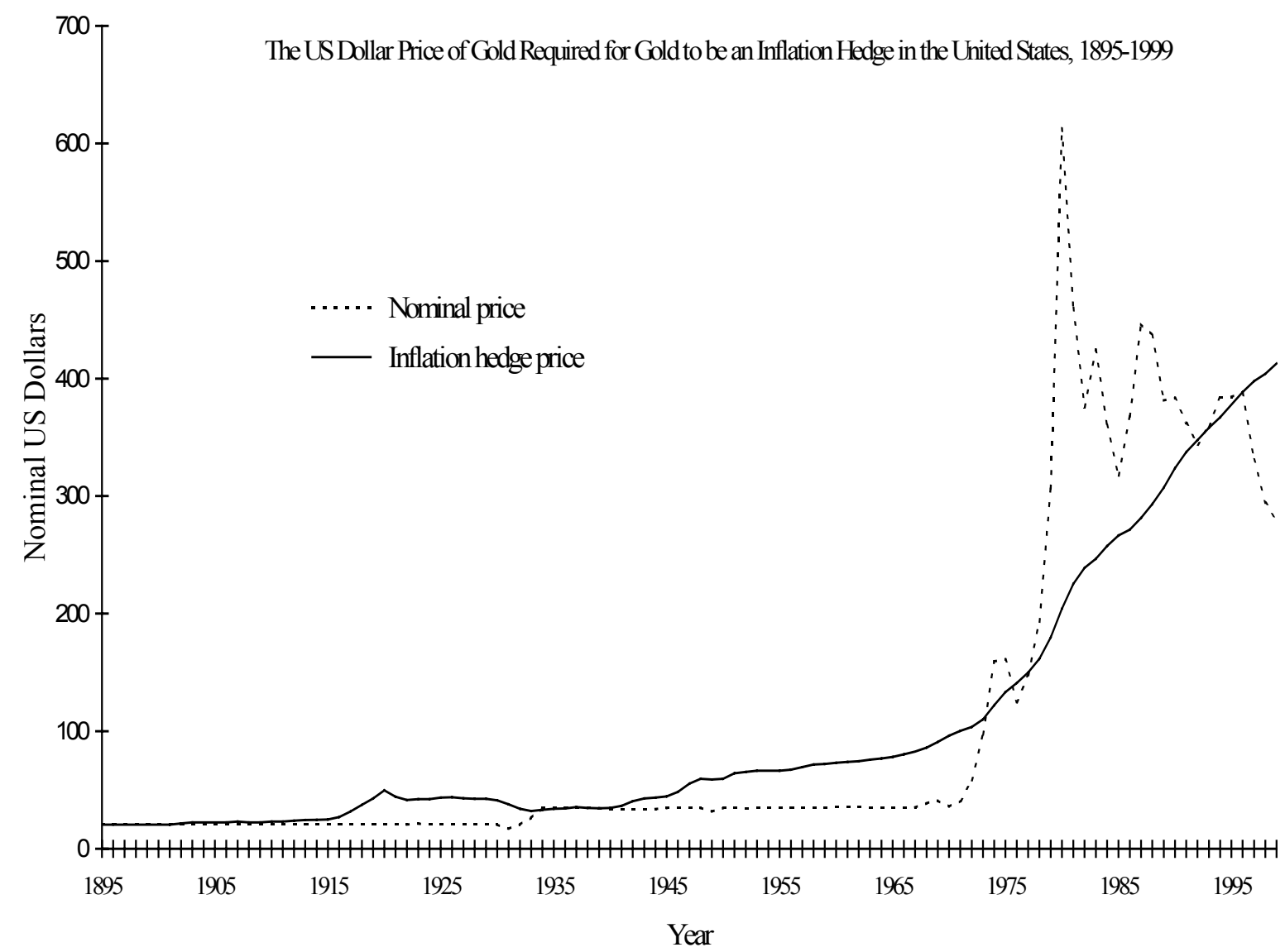

elasticity of gold with respect to the US Consumer Price Index (CPI) is 1.1. Long-run investment in gold appears to be an effective long-run inflation hedge.

Over the last few decades, however, gold has not been a reliable hedge against inflation. The nominal price of gold was \$384 (per ounce) in January 1982 and \$283 in December 1999. The price of gold would need to have risen to $\$ 691$ by November 1995 in order for it to be an inflation hedge for investors in the United States. In other words, the real wealth of an investor in the USA buying gold in January 1982, and holding it until December 1999, would have fallen to 41 per cent of the value of the initial investment--a loss of 59 per cent in real value. The equivalent losses for investors in United Kingdom, Germany, France and Japan adopting a similar "buy and hold strategy" over the same period after allowing for movements in dollar prices and exchange rates are 59 per cent, 58 per cent, 54 per cent and 74 per cent. Gold was not a short-run inflation hedge between 1982 and 1995. 
Previous approaches aimed at modelling the price of gold can be grouped into three categories. The first approach (e.g. Ariovich, 1983; Dooley, Isard and Taylor, 1995; Sherman, 1982, 1983, 1986; Sjaastad and Scacciallani, 1996) models variation in the price of gold in terms of variation in main macroeconomic variables such as exchange rates, interest rates, world income and political shocks. The second approach (e.g. Baker and Van Tassel, 1985; Diba and Grossman, 1984; Koutsoyiannis, 1983; Pindyck, 1993) focus on speculation or the rationality of gold price movements. The third approach (e.g. Chappell and Dowd, 1997; Kolluri, 1981; Laurent, 1994; Mahdavi and Zhou, 1997; Moore, 1990) examines gold as a hedge against inflation with a particular emphasis on short-run and long-run relationships between gold and the general price level. In this paper we attempt to reconcile the apparent inconsistency between significant short-run price volatility and long-run movements in the price of gold.

The remainder of the paper is organised as follows. Section 2 examines the short-run determinants of the price of gold and presents an explanation for gold price volatility. Section 3 presents the theoretical conditions under which gold would be regarded as an inflation hedge and shows that these conditions do not hold in the short-run. In Section 4 an empirical analysis is carried out using monthly gold price data, covering the period 1975 to 1999 and cointegration regression techniques. A brief conclusion follows in Section 5.

\section{The Short-run Price of Gold}

\subsection{The Short Run Supply of Gold}

The exhaustible resource depletion literature states that price, $P$, exceeds marginal cost, $M C$, in competitive markets. This difference, $P-M C$, or "royalty" increases over time at the rate of interest in order to equalise the present value of the marginal ounce extracted in each time period (see Hotelling, 1931). Gold, unlike most other natural resources, however, 
can be reused an infinite number of times. In this sense it is never "depleted" in the same manner as fossil fuels and other non-renewable resources. Therefore, Hotelling's influential model is not suitable for explaining the price path of gold over time. It also follows that over time the effect of gold mining activity is to increase the total available stock of gold above ground and a large proportion of this above ground stock is held by central banks. For example, Callaghan (1991) estimates that over one-third of the world's total gold stock is held by central banks (see also, Kaufmann and Winters, 1989).

Since the early 1980 's, central banks have been willing to lease gold. Gold producers (i.e. mines) supply their customers by leasing gold from central banks' gold stocks, as well as extracting it from their mines (see O'Callaghan, 1991). More specifically (as is described below), central banks lend out gold to gold producers via bullion banks who in turn sell it on to their customers. Therefore, there are two ways that gold producers can supply their customers, through mining and/or leasing.

The total supply of gold to the market in any period $t, Q_{t}^{S}$, is the sum of gold extracted by the industry, $Q_{a t}^{S}$, plus gold leased to the industry by central banks, $Q_{b t}^{S}$. That is:

$$
Q_{t}^{S}=Q_{a t}^{S}+Q_{b t}^{S}
$$

Gold producers selling in the gold market are assumed to adopt profit maximising behaviour in a market of price takers. The law of diminishing marginal returns suggests that the quantity of gold supplied from extraction in any period $t$ is directly related to price, $P_{t}$, and inversely related to the amount of gold that must be extracted in order to repay central banks for gold leased in the previous period, $Q_{b t-1}^{S}$. The amount of gold that must be repaid to central banks, $Q_{t}{ }^{*}$, is the amount of gold leased in the previous period incremented by the physical rate of interest, $\operatorname{Rg}$ :

$$
Q_{t}^{*}=\left(1+R g_{t-1}\right) Q^{S}{ }_{b t-1}
$$


More generally, the supply of extracted gold available to the market will be:

$$
Q_{a t}^{S}=Q_{a}^{S}\left(P_{t}, Q_{b t-1}^{S}, \operatorname{Rg}_{t-1}\right)
$$

where $\partial Q^{S}{ }_{a} / \partial P>0, \partial Q_{a}^{S} / \partial Q_{b t-1}^{S}<0$, and $\partial Q_{a}^{S} / \partial R g_{t-1}<0$. This supply function is an upwards sloping supply curve (in price) augmented by gold lease repayment costs.

The quantity of gold supplied by central banks for leasing, $Q_{b}^{S}$, (and hence the maximum physical amount available for gold producers to lease) is determined by central bank lenders adjusting their stocks of gold towards the level where the physical rate of interest, $R g$, is equal to the convenience yield from holding gold, $C y$, plus a default risk premium, $\rho$. When gold is leased, the central banks forgo the convenience yield for one period on the gold loaned out in return for the interest gained in the form of the physical interest rate for one period. No-arbitrage requires that the central banks' convenience yield loss (adjusted for default risk), $C y+\rho$, be equal to the interest gain, $R g$. That is:

$$
R g_{t}=C y_{t}+\rho_{t}
$$

The net reward to central banks from leasing gold would be reduced by a fall in the physical interest rate, an increase in convenience yield or a rise in the default risk premium caused by for example political or financial turmoil. Therefore, the quantity of gold leased to the industry by central banks in period $t, Q^{S}$, is:

$$
Q_{b t}^{S}=Q_{b}^{S}\left(R g_{t}, C y_{t}, \rho_{t}\right)
$$

where $\partial \mathrm{Q}_{\mathrm{b}}^{\mathrm{S}} / \partial \mathrm{Rg}>0, \partial \mathrm{Q}_{\mathrm{b}}^{\mathrm{S}} / \partial \mathrm{Cy}<0, \partial \mathrm{Q}_{\mathrm{b}}^{\mathrm{S}} / \partial \rho<0$. This supply function relates the supply of gold leased from central banks to the physical interest rate, the convenience yield and the default risk. It is important to note that the supply of gold leased is not related to the market price of gold, $P$.

It follows that the total supply of gold, $Q^{S}$, combines Eqs. (3) and (5): 


$$
Q_{t}^{S}=Q^{S}\left(P_{t}, Q_{b t-1}^{S}, R g_{t}, R g_{t-1}, C y_{t}, \rho_{t}\right)
$$

Lagging Eq. (5) one period and substituting for $Q_{b t-1}^{S}$ into Eq. (6) gives:

$$
Q^{S}{ }_{t}=Q^{S}\left(P_{t}, R g_{t}, R g_{t-1}, C y_{t}, C y_{t-1}, \rho_{t}, \rho_{t-1}\right) .
$$

In other words, the total supply of gold depends on the current price of gold and current and lagged values of the physical interest rate, the convenience yield, and default risk premium.

\subsection{The Short-run Demand for Gold}

As mentioned above, the demand for gold, $Q^{D}$, consists of a use demand for gold, $Q^{D}$, and an asset demand for gold, $Q^{D}$. Therefore, the total demand for gold is simply:

$$
Q_{t}^{D}=Q^{D}{ }_{U t}+Q_{A t}
$$

The use demand for gold refers to gold used in the production of goods and services. Therefore, like any input into a production process, one would expect use demand to be primarily a function of price:

$$
Q_{U t}^{D}=Q_{U}^{D}\left(P_{t}\right)
$$

where $d Q^{D}{ }_{U} / d P<0$.

The asset demand for gold, $Q^{D}$, can be considered as "gold as an investment" since it is believed that the negative beta of gold, $\beta g$, reduces portfolio risk (see Chua, Sick and Woodword, 1990). The effectiveness of gold in reducing portfolio risk is inversely related to the value of $\beta g$, because $\beta g$ summarises the covariance between returns on gold and the returns on a well diversified portfolio of assets. If $\beta g$ rises for a period of time, the demand for gold as an investment falls during that period, but rises when the value of $\beta g$ subsequently reverts to its lower value. Consequently, the period demand for gold as an investment is negatively related to the current value of $\beta g$ and positively related to lagged values of $\beta g$. 
The "price" or forgone alternative of the reduced portfolio risk obtained from holding gold is the interest that is not earned from other financial assets. The real interest rate, $R$, represents the opportunity cost of holding gold instead of an interest-bearing bond. Therefore, the real interest rate and the beta for gold primarily determine the asset demand for gold:

$$
Q_{A t}^{D}=Q_{A}^{D}\left(R_{t}, \beta g_{t}, \beta g_{t-1}\right)
$$

where $\partial Q_{A}^{D} / \partial R<0, \partial Q_{A}^{D} / \partial \beta g<0$ and $\partial Q_{A}^{D} / \partial \beta g_{t-1}>0$.

It follows that the total demand for gold, $Q^{D}$, combines Eqs. (9) and (10):

$$
Q_{t}^{D}=Q^{D}\left(P_{t}, R_{t}, \beta g_{t}, \beta g_{t-1}\right)
$$

where: $P$ is the price of gold; $R$ is the real interest rate; and $\beta g$ is the beta for gold.

\subsection{Short-run Equilibrium}

Equilibrium in the gold market occurs where supply equals demand:

$$
Q_{t}^{S}=Q^{D}
$$

or from Eqs. [7] and [11]:

$$
Q^{S}\left(P_{t}, R g_{t}, R g_{t-1}, C y_{t}, C y_{t-1}, \rho_{t}, \rho_{t-1}\right)=Q^{D}\left(P_{t}, R_{t}, \beta g_{t}, \beta g_{t-1}\right)
$$

There is an arbitrage relationship that reduces the number of variables in this equilibrium relationship and also solves a potential problem in the empirical analysis with the measurement of the real interest rate. The real interest rate is central to the model described above but it is virtually impossible to obtain accurate empirical estimates of it. The gold leasing rate can be used as an empirical proxy for the real interest rate (see Levin, Abhyankar and Ghosh, 1994). Central banks lend out gold at a physical interest rate to bullion banks 
who sell the gold, use the proceeds to buy a bond which earns interest, and at the same time place a forward contract for gold to repay the gold loan at the end of the period.

Arbitrage will drive this "trade" between central banks, the bullion banks and the gold producers to the point where:

$$
P_{t}\left(1+i_{t}\right)=P_{t}\left(1+R g_{t}\right)\left(1+\pi g_{t}\right)
$$

where: $i$ is the one-period interest rate on the bond; $\pi$ is the expected rise in the general price level; and $\pi g$ is the expected rise in the price of gold. The Fisher equation can be used to decompose the one-period interest rate into an expected inflation rate component, $\pi$, and a real interest rate component, $R$ :

$$
\left(1+i_{t}\right)=\left(1+R_{t}\right)\left(1+\pi_{t}\right)
$$

Substituting Eq. [15] into [14] gives:

$$
\left(1+R_{t}\right)\left(1+\pi_{t}\right)=\left(1+R g_{t}\right)\left(1+\pi g_{t}\right) .
$$

Eq. [16] shows that $R g$ (which is observable) can be used as a proxy for $R$ (which is not observable) if the price of gold is expected to rise at the general rate of inflation.

If the marginal cost of gold extraction, $M C g$, rises at the general rate of inflation, $\pi$, then:

$$
M C g_{t+1}=M C g_{t}\left(1+\pi_{t}\right) .
$$

If the price of gold is equal to the marginal cost of extraction (which would be the case in a competitive market) then:

$$
P_{t+1}=M C g_{t}\left(1+\pi_{t}\right)
$$

which implies that the price of gold is expected to rise at the general rate of inflation:

$$
P_{t+1}=P_{t}\left(1+\pi_{t}\right) .
$$


In other words, $\pi g=\pi$ in Eq. [16]. Consequently, the real interest rate is equal to the physical interest rate, $R=R g$. Therefore $R$ and $R g$ are equivalent and can be measured by subtracting the observable gold forward rate, $\pi g$, from the observable interest rate, $i$. This measure also contains a default premium which cannot be separated out (see Levin, Abhyankar and Ghosh, 1994).

$R$ and $\operatorname{Rg}$ are equal in equilibrium. This equivalence implies that the real interest rate need no longer appear directly in the equilibrium given in Eq. [13]. It is important however to recognise the significance of the real interest rate in the determination of the price of gold through its impact on inventory and the convenience yield. For example, although an exogenous rise in convenience yield would cause the price to rise, a rise in the convenience yield caused by a rise in the real interest rate would cause a reduction in the price of gold. More specifically, a rise in the real interest rate would cause central banks to reduce their inventories because the convenience yield of holding gold is now lower than the foregone alternative, the real interest rate. This sale of gold would lower the price of gold, and raise convenience yield to the level of the higher real interest rate at a new lower inventory.

Assuming linear functional forms for the supply and demand expressions [see Eq.(13)]:

$$
\begin{aligned}
& Q_{t}^{S}=a P_{t}+b R g_{t}-c R g_{t-1}-d C y_{t}+e C y_{t-1}-f \rho_{t}+g \rho_{t-1} \\
& Q^{D}=-h P_{t}-i R_{t}-j \beta g_{t}+k \beta g_{t-1}
\end{aligned}
$$

and setting $R_{t}=R g_{t}$ and solving for $P_{t}$ gives:

$$
\begin{array}{r}
P_{t}=-\frac{b+i}{a+h} R g_{t}+\frac{c}{a+h} R g_{t-1}+\frac{d}{a+h} C y_{t}-\frac{e}{a+h} C y_{t-1}+\frac{f}{a+h} \rho_{t} \\
-\frac{g}{a+h} \rho_{t-1}-\frac{j}{a+h} \beta g_{t}+\frac{k}{a+h} \beta g_{t-1}
\end{array}
$$


where the derivatives with respect to price are :

$\frac{\delta P_{t}}{\delta R g_{t}}<0 ; \frac{\delta P_{t}}{\delta R g_{t-1}}>0 ; \frac{\delta P_{t}}{\delta C y_{t}}>0 ; \frac{\delta P_{t}}{\delta C y_{t-1}}<0 ; \frac{\delta P_{t}}{\delta \rho_{t}}>0 ; \frac{\delta P_{t}}{\delta \rho_{t-1}}<0 ; \frac{\delta P_{t}}{\delta \beta g_{t}}<0 ; \frac{\delta P_{t}}{\delta \beta g_{t-1}}>0$

Increases in the current beta for gold and the current physical interest rate have an unambiguous negative effect on the price of gold, while increases in the current convenience yield and current default risk have an unambiguous positive impact on the price of gold. Lagged values of beta for gold and the physical interest rate have positive effects on the price of gold, while lagged values of the convenience yield and default risk have a negative effect on the price of gold.

\section{The Long-run Price of Gold}

Gold producers supply their customers both by extracting gold from mines and by leasing from central banks. If gold producers are profit maximisers, then they will substitute between the two alternative supply strategies to the point where:

$$
M C_{a}=M C_{b}
$$

and the marginal cost of strategy "a" (e.g. mining) equals the marginal cost of strategy "b" (e.g. leasing). As discussed above, in a competitive market the price of gold equals the marginal cost of extraction which in turn equals the marginal cost of leasing. That is:

$$
P_{t}=M C_{a t}=M C_{b t}
$$

The marginal cost to the mine of supplying one ounce of gold in the current period by "borrowing" it for one period from a central bank, $M C_{b t}$, is equal to the present value of mining one ounce plus the physical rate of interest to be returned to the central bank in the next period. That is: 


$$
M C_{b t}=\frac{M C_{a t}\left(1+R g_{t}\right)\left(1+\pi_{E t}\right)}{\left(1+R_{t}\right)\left(1+\pi_{t}\right)}
$$

where $\pi_{E}$ is the rate of increase in the costs associated with extracting gold and $\pi$ is the general rate of inflation. As explained above, if the marginal cost of gold extraction rises at the general rate of inflation, then:

$$
M c_{a t+1}=M C_{a t}\left(1+\pi_{E t}\right) .
$$

Eqs. [24] and [25] imply that as long as extraction costs rise at the general rate of inflation, $\pi_{E}=\pi$, and $P=M C_{a}$, (or $P$ is proportional to $M C_{a}$ if gold mines have market power), and the price of gold will rise at the general rate of inflation.

\section{Empirical Analysis}

\subsection{Measurement}

In this section, we use cointegration regression techniques to model gold price movements between January 1976 and December 1999. The model is of the basic structure:

$$
P g=f(P u s a, P w, R g, Y, \beta g, e r, \theta)
$$

where: " $P g$ " is the nominal USA dollar price of gold; " $P u s a$ " is the USA price index; " $P w$ " is the world price index; " $R g$ " is the gold lease rate; " $Y$ " is world income; " $\beta_{g}$ " is gold's "beta"; "er" is the dollar/world exchange rate; and " $\theta$ " are random financial and political shocks that impact on the price of gold.

The price of gold $(\mathrm{Pg})$ is the monthly average spot dollar price per ounce (www.kitco.com). Two general price level variables are included: (1) "USA Retail Price Index" (Pusa) (www.stats.bls.gov); and (2) "non-adjusted IMF World Consumer Price Index" $(P w)$, which measures overall "world price level”(Datastream). The gold lease rate $(R g)$ is calculated by subtracting the three-month gold forward rate from three-month LIBOR dollar 
interest rate. We are indebted to Mr. Andrew Smith of Mitsui Global Precious Metals for providing gold lease rates for the period January 1982 to December 1999. Gold was not leased every day during the early years. Therefore we avoid the problem of stale prices by using price and rates averaged over the month for the entire sample period.

A monthly index of real world income $(Y)$ was constructed using data obtained from Datastream and the OECD (http://www.oecd.org). Gold's beta $(\beta g)$ for each month $t$ was estimated by regressing the monthly gold return on the monthly $S \& P 500$ (dividends reinvested) return, based on information from the previous 36 months. The $S \& P 500$ total returns index was obtained from the website (www.economagic.com). The spot dollar/world currencies exchange rate (er) controls for gold dollar price movements attributable to gold market activity outside of the dollar area caused by exchange-rate-determined changes in the non-dollar gold price. The exchange rate (er) was measured as the "nominal major currencies dollar index", obtained from the Federal Reserve Board (www.bog.frb.fed.us). .

Default risk $(\rho)$ is associated with financial shocks, political turmoil and structural changes in the international economy. For example, a financial shock occurred following the collapse of Drexel Burnham Lambert in 1990 with large outstanding gold liabilities to central banks. Examples of political turmoil include the Malvinas and Gulf wars and the fall of the Berlin Wall. An example of international structural change that influenced the demand for gold is the transformation of India's economy from government-control to a market. The Hudson political tension index used by Ariovich (1983) and Sherman (1983) is no longer available. In the empirical analysis we model the impact of these shocks on the default risk associated with the gold lease rate by the inclusion of a series of time-specific dummy variables $(\theta)$. The statistically based criteria for including dummies are described below. 
Finally, in the analysis all the variables except $R g$ and $\beta g$ are expressed in natural logarithms (i.e. $\ln X)$. All data are available from 1976 with the exception of the gold lease rate which is only available from 1982. Since our aim is to model the nominal price of gold over the entire period that gold has freely floated, we estimate our model from the beginning of 1976 until the end of 1999, treating the gold lease rate as a missing variable until 1982, by constraining its effect to be zero.

\subsection{Long-run Relationships}

A variable is said to be integrated of order $d$ (or is $I(d)$ ) if it is required to be differenced " $d$-times" in order for the variable to become a stationary, invertible, nondeterministic, ARMA process (see Hendry, 1986). Most applied work that makes use of nonstationary data focuses upon $I(1)$ variables, that is variables that have a unit root. If a linear combination of two or more $I(1)$ variables are found to be stationary $(I(0))$, a long-run relationship between the variables exists and they are said to be cointegrated (see Engle and Granger, 1987).

The theoretical model outlined above suggests that if gold is an effective long-run inflation hedge (the log of) the price of gold, $\ln P g$, may be cointegrated with $\ln P u s a, \ln P w$ or a linear combination of the two price variables, and implies a cointegrating relationship of the following form:

$$
\alpha \ln P g_{t}=m+\beta \ln P u s a_{t}+\rho \ln P w_{t}+\omega_{t}
$$

where $\omega_{t}$ is a white noise process and $m$ represents possible non-stochastic elements of the vector (such as a constant or time-trend).

Engle and Granger (1987) have proved that if two or more variables are cointegrated it implies the existence of a well-defined error correction mechanism $(E C M)$. The ECM 
describes the short-run adjustment process of the cointegrated variables after a movement away from the long-run relationship. Given Eq.(28), a meaningful ECM is of the form:

$$
e c m_{t-1}=\gamma\left(\alpha \ln P g_{t-1}-\beta \ln P u s a_{t-1}-\rho \ln P w_{t-1}\right)
$$

where $\gamma$, the speed of adjustment parameter, which lies between 0 and -1 .

In order to establish the existence of a long-run relationship we first establish the order of integration of the variables through the use the "augmented Dickey -Fuller" $(A D F)$ test of a unit root (Dickey and Fuller, 1979, 1981). However, the results of our unit root tests are inconclusive. We are unable to reject the null of a unit root for $\ln P g$. There is also evidence that $\ln P u s a$ and $\ln P w$ are also I(1) processes. However, this conclusion is sensitive to the specific criterion used to select the lag used in our unit root tests. In some instances it is possible to reject the null of a unit root for $\ln P u s a$ and $\ln P w$, in favour of the alternative of $I(0)$ processes. In what follows below, we proceed under the assumption that $\ln P g, \ln P u s a$ and $\ln P w$ are all $\mathrm{I}(1)$ variables. We have decided to adopt such a strategy for two reasons. The first is that it is common to do so in the applied literature. Unit root tests have relatively low power and practitioners often rely on theoretical arguments to construct models based on cointegration methods when the results of unit root tests are inconclusive (see Engle and Granger, 1987; Muscatelli and Hurn, 1992; Hall, 1986). The second is that such an assumption allows us to pursue the possibility of long-run relationships through the use of cointegration methods, which is a key feature of our theoretical model.

The next step in our analysis is to establish whether a cointegrating relationship exists between $\ln P$ and $\ln P u s a$ and $\ln P w$, and if so, the precise form of this relationship. If the appropriate measure of the general price level is a linear combination of $\ln P u s a_{t}$ and $\ln P w_{t}$ we would expect to find the restrictions $\alpha=-1$ and $\beta+\rho=1$ in Eq. (28) hold. The specific methods used are those developed by Johansen $(1988,1991)$, The procedure produces two test 
statistics: a likelihood ratio test statistic based on the maximum eigenvalue of the stochastic matrix of the cointegrating vector autoregression and a likelihood ratio test statistic based on the trace of the same matrix. Both the maximum eigenvalue and trace tests suggest the existence of a single cointegrating vector. Having established the existence of a cointegrating vector the next step is to estimate $\alpha, \beta$ and $\rho$. This is achieved by normalising one of the coefficients (in this case we set $\alpha=1$ ). We find both $\beta$ and $\rho$ to be non-zero. However, a likelihood ratio test of the restrictions suggested by Eq. (28) is rejected.

One possible explanation for this rejection is the high correlation that exists between $\ln P u s a$ and $\ln P w(0.997$ in levels and 0.175 in first differences). This strong relationship suggests it may be legitimate to remove one or other of the price level terms from our cointegrating vector. When $\ln P w$ is excluded (essentially setting $\rho=0$ ) the results are mixed, at the $95 \%$ level of significance, the trace test suggests the existence of one cointegrating vector. However, the maximum eigenvalue test results fail to give results that are easily interpreted, at the 95\% significance level we would conclude there are no cointegrating vectors, and at the $90 \%$ significance level we would conclude there are two.

Such a finding is not uncommon (see for example Pesaran and Pesaran,1997), and in order to further investigate the relationship between the nominal price of gold and the price level we will assume the two variables are cointegrated. Note that if the two variables are not cointegrated we will not be able to establish a sensible ECM. A test of the restriction, $\alpha=1$ and $\beta=-1$ cannot be rejected at the $90 \%$ significance level (although it can at the $95 \%$ level of significance). We will therefore also proceed under the assumption that these restrictions hold (i.e. we have a unitary cointegrating vector). Finally, when $\ln P u s a$ is dropped from Eq. (28), both tests suggest there is no cointegration between $\ln P g$ and $\ln P w$. 
The cointegration tests provide some evidence for concluding that the retail price index in the United States and the nominal price or gold are involved in a long-run relationship. The tests also suggests that the implied elasticity of this relationship is one i.e. $(d \ln P g / d \ln P u s a=1)$ which is consistent with gold being a long-run hedge against inflation.

\subsection{Short-run Relationships}

In order to explore the short-run dynamics of the model, a equation of the following general form is estimated over the period 1976(1) to 1999(12):

$$
\begin{aligned}
\Delta \ln P g_{t} & =\alpha+a A(L) \Delta l n P g_{t-1}+b B(L) \Delta \ln P u s a_{t}+c C(L) \Delta \ln P w_{t}+d D(L) \Delta R g_{t} \\
& +e E(L) \Delta \ln Y_{t}+f F(L) \Delta \beta g_{t}+g G(L) \Delta \ln E R_{t}+\theta_{k} t_{t}+\gamma e c m_{t-1}+u_{t}
\end{aligned}
$$

where: " $\alpha$ " is a constant; $A(L), B(L), \ldots, G(L)$ are finite order lag polynomials; "a", "b", ..., "g" are vectors of the parameters associated with these lag polynomials; $\theta_{k}$ is an empirically determined set of period specific $\left(t_{k}\right)$ dummy variables; " $u$ " is a random error term; "ecm $m_{t-1}$ " is the error correction mechanism constructed from the results of the cointegration tests, that is we assume a cointegrating relationship between $\ln P g$ and $\ln P u s a$ and a unitary cointegrating vector:

$$
e c m_{t-1}=\ln P g_{t-1}-\ln P u s a_{t-1}
$$

We should note that $\ln Y_{t}, \beta g_{t}$ and $\ln E R_{t}$ are $I(1)$ variables, stationary upon first differencing. However, unit root tests suggest $R g_{t}$ may be stationary (this result depends upon the lag selection criterion chosen for the unit root test). We include the interest rate variable in first differences since specifications that "mix" variables in levels with variables in differences often badly fail residual tests, with serial correlation proving to be a serious problem. Furthermore, such models are typically difficult to interpret in terms of the hypothesis suggested by the underlying theory. 
The parameters of this model were estimated following Hendry's "general to specific" strategy (see for example Davidson et. al. 1978). We started with the general model outlined in Eq. [30] that contains all those variables that we believe (from our theoretical discussion) will influence the price of gold in the short-run. To begin with, we use six lags to fully investigate the rich dynamics of the theoretical model. It is important to note that lagged values of $e c m_{t-1}$ and the contemporaneous value of $\Delta l n P u s a$ are not included since this would result in simultaneity bias.

We then estimated the model without including any period specific dummies. We carried out a number of tests in order to evaluate the suitability of this specification. These tests included: 1) a Lagrange multiplier test of residual correlation (see Godfrey 1978a, $1978 b)$; 2) the Ramsey (1969) RESET test of functional form misspecification, using the square of the fitted values; 3) the Bera and Jarque's (1981) normality test of the residuals; and 4) a Langrange Multiplier test of heteroskedasticity based on the regression of squared residuals on squared fitted values (see Pesaran and Pesaran 1997). This empirical model did not perform well on these tests with the null hypotheses of normality, homoskedasticity and no functional form misspecification being solidly rejected.

A careful examination of a plot of the residuals from this model suggested a number of clear outliers that were likely responsible for the failure of these tests. We then included a number of time-specific dummy variables in the model in order to "dummy out" the effect of these outliers. The inclusion of these dummies resulted in a well-specified model that passes the above tests (test statistics given below). In order to make the model more parsimonious, we reduced the number of right-hand side variables by eliminating variables with statistically insignificant parameters. This was accomplished by testing for zero restrictions using a Wald (1949) test. This process was continued until the following "final" model was arrived at: 


$$
\begin{aligned}
& \Delta \ln P g_{t}=-0.0129+0.228 \Delta \ln P g_{t-1}-0.164 \Delta \ln P g_{t-2}+0.114 \Delta \ln P g_{t-5}+1.87 \Delta \ln P u s a_{t-3}+1.53 \Delta \ln P u s a_{t-6} \\
& {\left[\begin{array}{llllll}
3.4] & {[5.0]} & {[4.0]} & {[2.9]} & {[2.6]}
\end{array}\right]} \\
& -0.0148 \Delta R g_{t}-0.0134 \Delta R g_{t-5}+0.262 \Delta R g_{t-6}-0.108 \Delta \beta g_{t}-0.0520 \Delta \beta g_{t-2}+0.0454 \Delta \beta g_{t-5} \\
& {\left[\begin{array}{llllll}
2.0] & {[1.7]} & {[3.2]} & {[3.7]} & {[1.8]}
\end{array}\right.} \\
& -0.671 \text { Aner }_{t}-0.0228 \text { ecm }_{t-1}+0.105 t_{76(11)}-0.108 t_{78(11)}+0.159 t_{79(9)}+0.147 t_{79(12)} \\
& {\left[\begin{array}{llllll}
5.6] & {[3.1]} & {[3.2]} & {[3.3]}
\end{array}\right]} \\
& +0.379 t_{80(1)}-0.0962 t_{80(2)}-0.0826 t_{81(7)}-0.103 t_{82(3)}+0.0957 t_{82(4)}-0.174 t_{82(9)} \\
& {\left[\begin{array}{lllll}
11.0] & {[2.5]} & {[2.4]} & {[3.1]} & {[2.9]}
\end{array}\right]} \\
& -0.0917 t_{91(2)}+0.115 t_{99(10)}-0.119 t_{99(11)}+u_{t} \\
& {[2.7] \quad[3.5] \quad[3.2]}
\end{aligned}
$$

The absolute value of each parameter's associated t-statistic is shown in parentheses.

The $R^{2}$ value of this model is 0.65 , a good fit for a model in first differences. The Lagrange multiplier test for serial correlation suggests no significant serial correlation is present: $\chi^{2}(12)=7.6$ with a $p$-value $=0.82$ (the correlogram of the residuals is also indicitive of a white noise process). The Ramsay RESET test for functional form suggests that the model is not misspecified: $\chi^{2}(1)=1.1$ with a $p$-value $=0.30$. The Bera-Jarque test for normality indicates that the residuals are normally distributed: $\chi^{2}(2)=1.4$ with a $p$-value $=$ 0.49. The test based on the regression of squared residuals on squared fitted values indicates that no significant heteroskedasticity is present: $\chi^{2}(1)=0.5$ with a $p$-value $=0.48$. Based on these tests serial correlation, non-normality, heteroskedasiticity and functional form misspecification are not problems.

Overall, the parameters estimates are consistent with the main hypotheses suggested by the theoretical model regarding the determinants of short-run movements in the price of gold. Lagged values of $\Delta \ln P g$ are statistically significant at 1,2 and 5 months. This finding that past values in the changes in the price of gold are predictive is not unusual in studies of asset pricing (e.g. exchange rates and stock prices). This apparent predictability may be 
capturing the speculative behaviour of chartists, noise traders and other investors or more generally points to the possibility that the gold market is not an "efficient market".

Lagged values of $\Delta \ln P u s a$ are statistically significant at 3 and 6 months. These positive effects of "recent" USA inflation ( $\Delta l n P u s a_{t-3}$ and $\left.\Delta l n P u s a_{t-6}\right)$ on the price of gold can be explained by short-run increases in the demand for gold that occur caused by inflation hedging. In other words, investors tend to hold less gold during periods of low inflation. This means that, quite apart from the long run price of gold rising with the overall price level, there are short-run changes in demand that impact on price.

The current value and two lagged values of $\Delta R g$ are statistically significant. The theory suggests that high current gold leasing rates depress the price of gold by increasing the supply of gold offered to the market by central banks. The theory also suggests that high gold leasing rates depress the price of gold by decreasing the demand for gold. Gold leasing rates are closely associated with real interest rates and a high real interest rate represents a high opportunity cost of holding gold relative to other interest-bearing investments. Therefore the gold lease rate (which should be equal to the real interest rate, apart from the default premium) both increases central banks' supply and reduces investors' demand for gold, thereby depressing the price. The negative signs on the parameters of $\Delta R g_{t}$ and $\Delta R g_{t-5}$ may reflect these effects. However, the theory also suggests that current gold lease repayments to central banks should be positively related to earlier period high gold leasing rates. These repayments reduce the current supply of gold to the market and this in turn should increase the price of gold. The positive sign on the parameter of $\Delta R g_{t-6}$ may indicate this effect.

The current value and two lagged values of $\Delta \beta g$ are statistically significant. The highly desirable diversification property of gold is associated with its negative beta. Therefore gold is less attractive to hold in portfolios during periods when its beta is relatively 
high, and the gold price should fall in response to the lower investment demand for gold. This effect may be picked up by the negative signs on the parameters of $\Delta \beta g_{t}$ and $\Delta \beta g_{t-5}$. The positive parameter on $\Delta \beta g_{t-6}$ may indicate the effect of an increased short-run demand for gold as holdings of gold in portfolios revert to "normal" following a period when holdings of gold in portfolios were reduced because gold's beta was high.

The current value of $\Delta l n e r$ is statistically significant. The negative sign on the parameter of the dollar/world exchange rate is consistent with the theory. The demand for gold by non-USA investors falls in response to a rise in er because this change in the exchange rate would raise the price of gold expressed in non-dollar currencies to non-USA investors. When the dollar "strengthens", the price of gold rises for investors outside the dollar area even though the dollar price remains constant. Therefore a rise in er causes a reduction in demand for gold that depresses the dollar price of gold. If the gold market was entirely dominated by investors inside of the dollar area, the magnitude of the parameter estimate would be zero because movements in this exchange rate would be irrelevant. On the other hand, if the gold market was entirely dominated by investors outside of the dollar area, the magnitude of the parameter estimate would be minus unity. The finding that the magnitude of this parameter is -0.671 suggests (not surprisingly) that substantial components of the gold market lie both inside and outside the dollar area.

It is important to note that both $\Delta \ln Y$ and $\Delta \ln P w$ do not enter the final specification as significant variables. This suggests that world income and world inflation are not important determinants of the price of gold. The finding that short-run changes in world income are not important is surprising but may be caused by the fact that we had to interpolate this variable from annual growth rates. However the finding that world inflation is not important is easier to justify. $P w$ was included in order to control for the possibility of an additional impact on 
the dollar price of gold caused by a change in the price of gold relative to other goods outside of the USA after holding er and Pusa constant. The absence of this variable in the final model indicates that the exchange rate tends to adjust in response to differences between the world inflation rate and the USA inflation rate.

In the final model there are thirteen statistically significant period-specific dummies. As discussed above it is difficult to precisely pinpoint the events that cause these sharp jumps and falls in the nominal price of gold. However, it is interesting to note that nine of these dummies cluster in the later 1970s and early 1980s. The late 1970s was a period of rapidly rising inflation (and inflation expectations) in the USA. More specifically in January 1977 the inflation rate was 4.5 per cent and by May 1980 it peaked at 13.3 per cent. After 1980 inflation fell rapidly reaching 3.5 per cent by January 1983. This inflation "spike" centred around 1980 likely caused increased volatility in inflation expectations which would impact on the price of gold in a manner not directly taken into consideration in our empirical model. We do not model the demand for assets that are believed to be hedges against inflation as a function of inflation because nominal interest rates should eliminate such a relationship via the Fisher relationship between nominal interest rates and expected inflation. Nevertheless, inflation volatility may well increase the demand for assets that provide hedges against inflation. However, this explanation is speculative.

The parameter of $e c m_{t-1}$ is -0.0228 . Therefore the error correction mechanism that we constructed is well behaved since it lies between 0 and -1 . The finding confirms that $\ln P g$ and InPusa are indeed cointegrated and lends further support to the hypothesis that these two variables move together in the long-run. However, the magnitude of this coefficient is "small" (i.e. closer to 0 than to -1 ). In addition, relative to some of the parameters in the short-run model it is also "small" in magnitude. This suggests that typically movements in the 
nominal price of gold are dominated by short-run influences and that the long-run relationship has less impact at any given point in time.

\section{Conclusion}

In this paper a theoretical model suggests that sizeable short-run movements in the price of gold are consistent with the gold price rising over time with the general rate of inflation. An analysis using monthly gold price data (1976-1999) and cointegration regression techniques provides empirical confirmation that gold can be regarded as a long-run inflation hedge. The analysis also confirms that movements in the nominal price of gold are dominated by short-run influences. Future research to extend this analysis would require examination of the assumptions made in this analysis. For example, the marginal cost of extracting gold may not rise at the rate of inflation. The convenience yield of gold may alter over time if gold ceases to be a reserve currency. The leasing rate may provide a biased measure of real interest rates if default risk is not a random variable. Finally, the supply of gold may not be a positive function of the price if high gold prices increase efforts to extract more gold from a smaller quantity of ore. 


\section{References}

Aggarwal, R., 1992, Gold Markets, in: Newman, P., Milgate, M., Eatwell, J. (eds.) The New Palgrave Dictionary of Money and Finance (Volume 2), Basingstoke, Macmillan, pp. $257-258$.

Akaike, H., 1974, A New Look at Statistical Model Identification, IEEE Transactions on Automatic Control, ac-19, pp. 716-23.

Ariovich, G., 1983, The Impact of Political Tension on the Price of Gold, Journal for Studies in Economics and Econometrics, vol. 16, pp. 17-37.

Bera, A.K., Jarque, C.M., 1981, An Efficient Large Sample Test for Normality of Observations and Regression Residuals. Working Papers in Economics no. 40, Canberra, Australian National University.

Baker, S. A., van Tassel, R.C., 1985, Forecasting the Price of Gold: A Fundamentalist Approach, Atlantic Economic Journal, vol. 13, pp. 43-51.

Chappell, D., Dowd, K., 1997, A Simple Model of the Gold Standard, Journal of Money, Credit and Banking, vol. 29, pp. 94-105.

Chua, J., Sick, G., Woodword, R., 1990, Diversifying with Gold Stocks, Financial Analysts Journal, vol. 46, pp. 76-79.

Davidson, J. E. H., Hendry, D. F., Srba, F., Yeo, S., 1978, Econometric Modelling of the Aggregate Time-Series Relationship Between Consumers' Expenditure and Income in the United Kingdom, Economic Journal, vol. 88, pp. 661-92.

Diba, B., Grossman, H., 1984, Rational Bubbles in the Price of Gold, NBER Working Paper: 1300. Cambridge, MA, National Bureau of Economic Research. 
Dickey, D.A., Fuller, W.A., 1979, Distribution of the Estimators for Autoregressive Time Series with a Unit Root, Journal of the American Statistical Association, vol. 74, pp. 427-431.

Dickey, D.A., Fuller, W.A., 1981, Likelihood Ratio Tests for Autoregressive Time Series with a Unit Root, Econometrica, vol. 50, pp. 1057-1072.

Dooley, M.P., Isard, P., Taylor, M.P., 1995, Exchange Rates, Country-specific Shocks and Gold, Applied Financial Economics, vol. 5, pp. 121-129.

Engle, R.F., Granger, C.W.J., 1987, Cointegration and Error-Correction: Representation, Estimation and Testing, Econometrica, vol. 55, pp. 251-276.

Godfrey, L., 1978a, Testing against General Autoreggressive and Moving Average Error Models when the Regressors include Lagged Dependent Variables, Econometrica, vol. 46, pp. 1293-1301.

Godfrey, L., 1978b, Testing for Higher Order Serial Correlation in Regression Equations when Regressors include Lagged Dependent Variables, Econometrica,vol.46,1303-10.

Gooding, K., 1997, Demand for Gold at Record Levels, Financial Times (Nov. 20), p. 30.

Hall, S.G., 1986, An Application of the Engle-Granger Two Step Estimation Procedure to United Kingdom Aggregate Wage Data, Oxford Bulletin of Economics and Statistics, vol. 48 , pp. $229-240$.

Hendry, D.F., 1986, Econometric Modelling with Cointegrated Variables: An Overview, Oxford Bulletin of Economics and Statistics, vol. 46, pp. 201-212.

Hotelling, H., 1931, The Economics of Exhaustible Resources, Journal of Political Economy, vol. 39, pp. 137-175.

Johansen, S., 1988, Statistical Analysis of Cointegration Vectors, Journal of Economic Dynamics and Control, vol. 12, pp. 231-54. 
Johansen, S., 1991, Estimation and Hypothesis Testing of Cointegration in Gaussian Vector Autoreggression Models, Economometrica, vol. 59, pp. 1551-80.

Kaufmann, T., Winters, R., 1989, The Price of Gold: A Simple Model, Resources

Policy, vol. 19, pp. 309-318.

Koutsoyiannis, A., 1983 A Short-Run Pricing Model for a Speculative Asset, Tested with Data from the Gold Bullion Market, Applied Economics, vol. 15, pp. 563-581.

Kolb, R., 1992, Is Normal Backwardation Normal?, Journal of Futures Markets, vol. 12, pp. 75-91.

Kolluri, B.R., 1981, Gold as a Hedge against Inflation: An Empirical Investigation, Quarterly Review of Economics and Business, vol. 21, pp. 13-24.

Laurent, R.D., 1994, Is There a Role for Gold in Monetary Policy?, Economic Perspectives (The Federal Reserve Bank of Chicago), vol. XVIII: pp. 2-14.

Levin, E., Abhyankar, A., Ghosh, D., 1994, Does the Gold Market Reveal Real Interest Rates?, Manchester School (supplement), vol. 62, pp. 93-103.

MacKinnon, J.G., 1991, Critical Values for Cointegration Tests in R.F. Engle and C.Granger, C.W.J. (eds), Long-Run Economic Relationships: Readings in Cointegration. Oxford, Oxford University Press.

Mahdavi, S., Zhou, S., 1997, Gold and Commodity Prices as Leading Indicators of Inflation: Tests of Long-Run Relationship and Predictive Performance, Journal of Economics and Business, vol. 49, pp. 475-489.

Moore, G., 1990, Gold Prices and a Leading Index of Inflation, Challenge, vol 33, pp. 52-56.

Muscatellii, V.A., Hurn, S., 1992, Cointegration and Dynamic Time Series Models, Journal of Economic Surveys, vol. 6, pp. 1-43.

O'Callaghan, G. 1991, The Structure and Operation of the World Gold Market, IMF 
Working Paper no. 91-120. Washington, International Monetary Fund.

Pesaran, M. H., Pesaran, B., 1997, Working with Microfit 4.0: Interactive Econometric Analysis, Oxford, Oxford University Press.

Pindyck, R.S., 1993, The Present Value Model of Rational Commodity Pricing, The Economic Journal, vol. 103, pp. 511-530.

Ramsey, J.B., 1969, Tests for Specification Errors in Classical Linear Last Squares Regression Analysis, Journal of the Royal Statistical Society, B, pp350-71.

Sjaastad, L.A., Scacciallani, F., 1996, The Price of Gold and the Exchange Rate, Journal of Money and Finance, vol. 15, pp. 879-897.

Sherman, E., 1986, Gold Investment: Theory and Application, New York, Prentice Hall.

Sherman, E. J., 1982, New Gold Model Explains Variations, Commodity Journal, vol. 17, pp. $16-20$.

Sherman, E., 1983, A Gold Pricing Model, Journal of Portfolio Management, vol. 9, pp 6870.

Smith, A., 1993, Precious Metals Outlook (March), London, Union Bank of Switzerland.

Schwarz, G., 1978, Estimating the Dimension of a Model, Annals of Statistics, vol. 6, pp. 461464.

Wald, A., 1943, A Note on the Consistency of the Maximum Likelihood Estimator, Annals of Mathematical Statistics, vol. 20, pp. 595-601.

World Gold Council, 1992, The European Guide to Gold Investment, London, World Gold Council. 
Figure 1

The US Dollar Price of Gold Required for Gold to be an Inflation

Hedge in the United States, 1895-1999

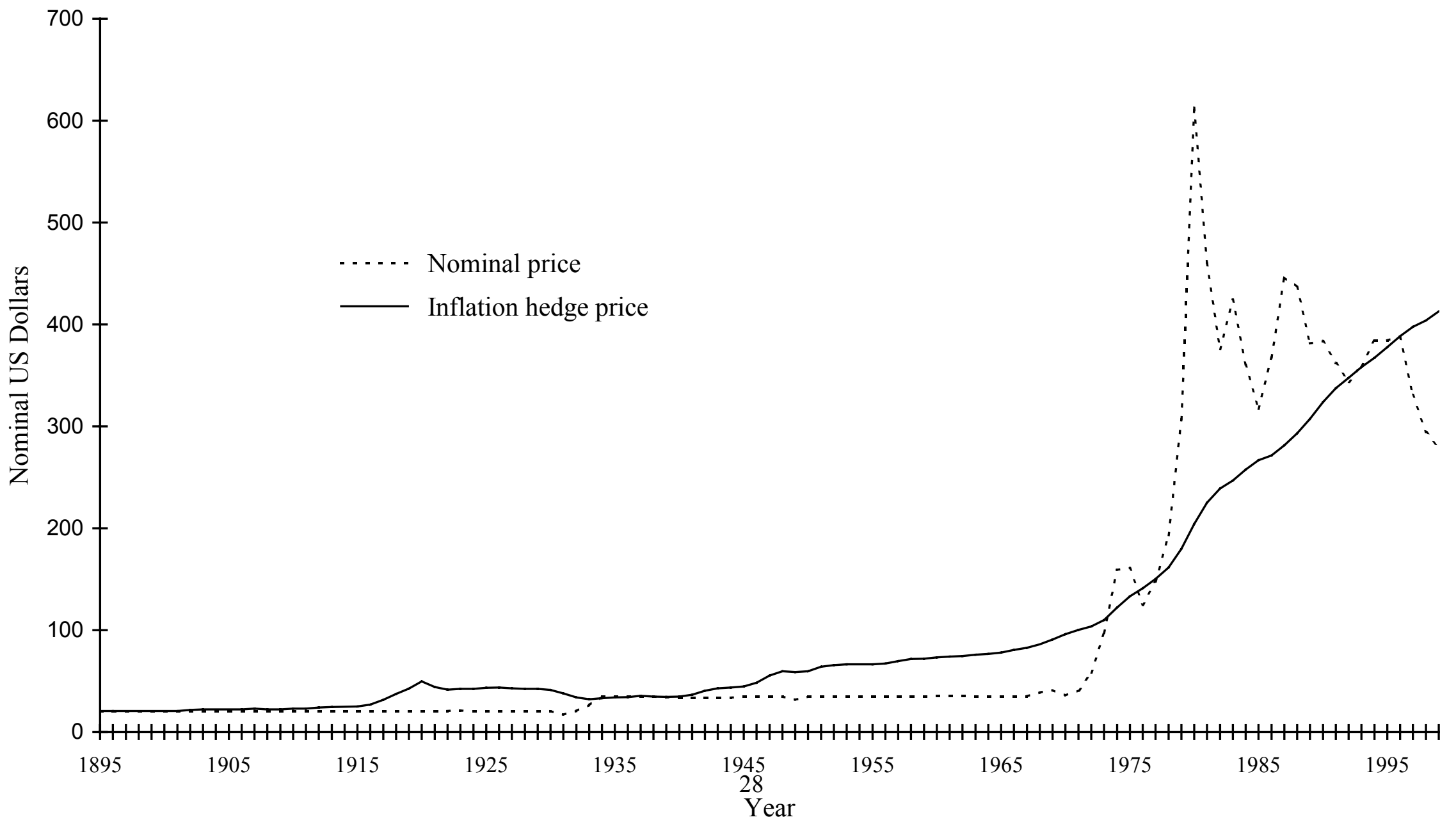

